\section{A biopolítica na genealogia da psicanálise: da salvação à cura}

\section{Biopolitics in the genealogy of psychoanalysis: from salvation to cure}

Joel Birman

Professor titular do Instituto de Psicologia Universidade Federal do Rio de Janeiro (UFRJ); professor adjunto do Instituto de Medicina Social (IMS) - Universidade do Estado do Rio de Janeiro (Uerj); pesquisador do Conselho Nacional de Pesquisa (CNPq)

Rua Marquês de São Vicente, 250

22451-040 Rio de Janeiro - RJ - Brasil regmarchese@globo.com.br
BIRMAN, Joel. A biopolítica na genealogia da psicanálise: da salvação à cura. História, Ciências, Saúde - Manguinhos, Rio de Janeiro, v.14, n.2, p.529-548, abr.-jun. 2007.

A intenção inicial deste ensaio, inscrito no campo da história das ciências, é circunscrever a passagem histórica do ideal da salvação para o da cura no Ocidente, indicando os efeitos do processo de medicalização do social realizado pela biopolítica. Em seguida, delineiam-se os diversos desdobramentos da biopolítica nos primórdios do discurso da psicanálise.

PALAVRAS-CHAVE: biopolítica; normatividade; normalização.

BIRMAN, Joel. Biopolitics in the genealogy of psychoanalysis: from salvation to cure. História, Ciências, Saúde - Manguinhos, Rio de Janeiro, v.14, n.2, p.529-548, Apr.-June 2007.

The initial aim of this essay is to sketch out the historical passage from the ideal of salvation to the ideal of cure in the West, indicating the effects of the process of medicalization of society attained through biopolitics. In second place, it is intended to describe the different ramifications of biopolitics in the origins of psychoanalysis discourse.

KEYWORDS: biopolitics; normativity; normalization. 


\section{O mal}

* Conferência

"La guérison em psychanalyse", realizada na jornada de estudos do Espace Analytique, em Bordeaux, França, 17 e 18 de junho de 2006.
$A \begin{gathered}\text { 'salvação' e a 'cura' indicam a existência de dois registros dife- } \\ \text { rentes de leitura, forjados pelas sociedades ocidentais para se }\end{gathered}$ defrontarem com a questão do 'mal', que as acossa e nelas se dissemina. Isso implica reconhecer, antes de tudo, que nas representações prevalentes no Ocidente o mal existe efetivamente, como aliás em outras tradições culturais. Não existe, pois, no que concerne a isso, qualquer dúvida.

É preciso enunciar ainda, em seguida, que o suposto mal é passível de ser interpretado de maneiras diferentes, conduzindo então a discursos e a práticas diversas, que se propõem a regulá-lo e que têm até mesmo a pretensão de extirpá-lo. Esses discursos e práticas se configuram em diferentes modalidades. Estas, com efeito, podem ser de ordem ética, religiosa e terapêutica, de acordo com as diferentes concepções e interpretações sobre o mal em questão, que foram forjadas ao longo da história do Ocidente.

Toda a tradição ocidental, da Antiguidade à modernidade, enunciou indiscutivelmente a presença eloqüente do mal na existência humana, mesmo que este tenha sido concebido de diferentes formas na cultura antiga e na que se iniciou com o cristianismo. Neste, com efeito, a responsabilidade e a culpa humanas foram colocadas no primeiro plano, inscrevendo-se, pois, na origem da experiência do mal. Isso porque as transgressões patentes, empreendidas pelos indivíduos aos preceitos divinos, estariam na origem daquela experiência. Na cultura grega, em contrapartida, os deuses estariam na gênese do mal, pois teriam enlouquecido os homens (Deleuze, 1962), esvaziando então relativamente a responsabilidade destes no engendramento daquele. Foi esta, com efeito, a leitura que Nietzsche (1977) nos sugeriu, para interpretar a relação da sociedade grega e do cristianismo com a problemática do mal.

Porém, o mal aqui em questão não é um mal qualquer, pois implica para o sujeito a constituição de certo campo ético que fundaria o seu ser. Ao lado disso, inscreve o dito sujeito e a ética em questão num espaço social de pertencimento. Pode-se enunciar assim, no que concerne a isso, que a relação do sujeito com as questões da vida e da morte se inscreve no centro dessa problemática. Qual é a melhor forma, para o sujeito, em que a vida poderia e deveria ser efetivamente vivida? Como os indivíduos poderiam e deveriam se defrontar com a inevitabilidade da morte? Foram estas questões cruciais que constituíram o campo ético a que me referi há pouco, delineando a inscrição dos sujeitos num espaço social de pertencimento.

A relação do sujeito com o mal, no entanto, não foi a mesma na tradição greco-romana e no cristianismo, repito, pois na primeira a responsabilidade humana na gênese do mal não era primordial, 
como ocorreu no cristianismo, no qual o sujeito foi culpabilizado. A disseminação das práticas de 'cuidado de si' no mundo helenístico evidencia efetivamente que através delas os indivíduos pretendiam não apenas viver melhor e incrementar a economia dos seus prazeres, como também se prepararem para morrer, conforme os preceitos éticos do estoicismo (Foucault, 2001). O que isso evidencia, portanto, é uma relação concreta desses sujeitos com a questão da 'finitude', que foi radicalmente transformada com o advento histórico do cristianismo.

Foi no contexto histórico do cristianismo, portanto, que a 'moral' da salvação se constituiu efetivamente, transformando radicalmente as coordenadas presentes no campo ético da Antiguidade. Assim, a relação do sujeito com o mal passou a se inscrever no registro eminentemente religioso. Em decorrência, a relação do sujeito com a finitude se apagou, sendo silenciada pela promessa cristã da vida eterna. Esta poderia ser garantida na cidade de Deus, enfim, desde que os indivíduos se regulassem pelos preceitos morais do cristianismo na cidade terrena, conforme o enunciado canônico formulado por santo Agostinho (Brown, 1971).

Facilmente depreende-se disso tudo que a relação do Ocidente com a problemática do mal foi reordenada radicalmente com a emergência histórica do cristianismo, pois a questão crucial do confronto humano com a sua finitude foi deslocada e silenciada, em nome da promessa da vida eterna na cidade de Deus. Foi aqui, efetivamente, que se constituiu o ideário da salvação na sua especificidade, na nossa tradição. Esse ideário foi subvertido, contudo, com a emergência da modernidade, que enunciou a problemática da cura com a constituição da medicina moderna.

Nesse contexto, a questão da finitude foi novamente colocada em cena, nas relações intricadas então tecidas entre os registros da 'vida' e da 'saúde', por um lado, e da 'morte' e da 'enfermidade', por outro. O correlato dessa transformação de ponta-cabeça, na relação da sociedade ocidental com o mal, foi a substituição do discurso da religião pelos da ciência e da política, na regulação do mal.

\section{Questão de método}

Assim, enunciar algo que seja significativo sobre o deslocamento da problemática da salvação para a da cura implica e supõe reconhecer, antes de tudo, que se trata de uma passagem de ordem histórica. Essa viragem histórica, no entanto, é o correlato de uma transformação antropológica de grande envergadura que ocorreu no Ocidente, no que concerne ao registro dos valores. Esta última mudança se desdobrou também numa gigantesca transformação epistemológica, da qual a dita medicina científica foi a resultante. 
Existem então na proposição que enunciei, de caráter teórico e metodológico, não apenas diversos registros de leitura e de códigos de interpretação, mas também uma ordem bem estabelecida nesses registros e códigos. Com efeito, se a 'história', a 'antropologia' e a 'epistemologia' implicam aqui uma ordem de exposição, não se pode esquecer que isso supõe também uma ordem da razão, antes de tudo.

Deve-se sublinhar devidamente que a epistemologia se inscreve somente no final da série enunciada, não no começo. O que se pressupõe, com isso, é certa perspectiva sobre os discursos das ciências, nos quais estes encontrariam inicialmente as suas condições concretas de possibilidade nos campos histórico e social, que seriam, em seguida, o solo de transformações de ordem antropológica, e que tudo isso, finalmente, se desdobraria em mudanças de ordem epistemológica. Vale dizer, a constituição do campo conceitual de um dado discurso científico seria inseparável do campo históricosocial e do solo antropológico onde aquele se inscreve.

Sobre isso, Canguilhem enunciou um preceito teórico e metodológico - num ensaio brilhante sobre "O objeto da histórica da ciência" (Canguilhem, 1968c) -, de que não se poderia separar a leitura 'interna' de um discurso científico da sua leitura 'externa', posto que esta seria o solo daquela. Com efeito, os registros histórico-social e antropológico que delineariam a leitura externa seriam então o solo para a leitura interna e conceitual do discurso científico. Numa perspectiva teórica próxima, pois retoma a leitura de Canguilhem numa retórica política e epistemológica marxista, Althusser (1965) destacou devidamente como um novo discurso científico se constituiria sempre pela ruptura epistêmica com um dado campo e horizonte ideológico que estaria já bem estabelecido numa dada tradição, de maneira que a leitura internalista de um discurso científico pressuporia sempre a leitura externalista. Finalmente, é preciso ainda evocar como as proposições teóricas de Foucault, sobre a arqueologia do saber (1968) e a genealogia do poder (1994), pressupõem também a mesma articulação entre a leitura interna e a leitura externa dos discursos científicos, mas numa outra direção de leitura, que certamente ultrapassa em muito o registro estrito da história das ciências.

No que concerne aos pressupostos de ordem teórica e metodológica que me orientaram neste ensaio, o que foi dito já é suficiente para que se dimensione devidamente o que virá em seguida. O que pretendo realizar aqui, acerca do deslocamento da problemática da salvação para a da cura, é destacar os pressupostos dessa passagem, antes de tudo. A biopolítica estará no centro desses pressupostos. Pretendo esboçar, em seguida, os desdobramentos dessa passagem crucial no campo do discurso psicanalítico que se constituiu com Freud, na virada do século XIX para o século XX. 


\section{Modernidade, medicalização e biopoder}

Pode-se afirmar que a passagem crucial da problemática da salvação para a da cura é um dos signos constitutivos da modernidade no Ocidente, realizado entre fins do século XVIII e início do século XIX. Acerca da 'modernidade', é preciso compreender que as sociedades ocidentais passaram a ser permeadas pelos discursos médicos, os quais passaram a regular desde então todas as práticas e laços sociais. Assim, a modernidade ocidental implicou uma 'medicalização' do campo social como um todo. Desde então, portanto, nada seria estranho e exterior ao olhar médico, que passou não apenas a interpretar a totalidade dos acontecimentos sociais, mas também a intervir sobre ela.

Assim, a nova leitura médica passou a substituir a anterior leitura religiosa desses acontecimentos. Foi nessa inflexão decisiva que o ideário da cura passou a ocupar o lugar até então atribuído ao da salvação. Porém a questão da cura se inscreveu num campo bem mais abrangente que é o da 'saúde', de maneira que a promoção desta passou a ocupar na modernidade a posição anteriormente concedida à moral da salvação (Foucault, 1963).

Se a promoção da saúde passou a ocupar essa posição axial, isso no entanto foi o correlato de uma nova configuração do campo social, no qual o biopoder (Foucault, 1976) se constituiu pelo estabelecimento do campo da 'biopolítica' (Foucault, 1997). Nessa transformação fundamental, contudo, a 'população' passou a ser o objeto por excelência do discurso da biopolítica (Foucault, 1976). Isso porque a 'qualidade de vida' da população foi então transformada na fonte maior da 'riqueza das nações' (Foucault, 1976). Na modernidade, com efeito, não seria apenas a posse de múltiplos recursos naturais que consubstanciaria a riqueza de um dado Estado, mas sim a qualidade de vida de seus trabalhadores.

Foi em decorrência disso que a 'medicina' assumiu um lugar estratégico nesse contexto, pois a produção de uma população saudável seria um dos signos eloqüentes de riqueza de um Estado. Ao lado disso, a 'pedagogia' assumiu também uma posição destacada, pois pela sua mediação seria forjada uma população bem educada, condição outra para a produção de riqueza das nações.

A medicina moderna se configurou então em duas vertentes e dimensões, que são efetivamente complementares. De um lado a medicina 'individual', isto é, a 'clínica'. De outro, a medicina 'social', pela qual o Estado, pela via da 'higiene social', transformou totalmente a paisagem das cidades pelos dispositivos sanitários (Foucault, 1963). Com efeito, da circulação de água às novas condições de aeração das construções civis, passando pela regulação dos excrementos e de outras dimensões sanitárias presentes no meio ambiente, a cidade passou a ser completamente perpassada pelos 
dispositivos médicos. Ao lado disso, a população passou a ser meticulosamente classificada em diferentes segmentos, de acordo com suas condições de saúde e doença, assim como as diversas regiões existentes no espaço urbano (Foucault, 1963). A demografia e a epidemiologia se constituíram, então, como instrumentos fundamentais da higiene social. Com isso, a cidade passou a ser esquadrinhada e cartografada nos seus menores detalhes, pelo olhar médico e pelos dispositivos sanitários de intervenção.

Essas duas dimensões da medicina moderna são intimamente articuladas e inseparáveis, seguramente. Com efeito, não se pode jamais esquecer que a medicina clínica supõe sempre a medicina social e vice-versa. Isso porque a racionalidade do particular, que foi fundante do campo da clínica, pressupõe a racionalidade estatística e probabilística, que foi o eixo constitutivo da higiene social (Foucault, 1963).

No centro estratégico dessa nova configuração médica, do espaço social e do discurso médico que lhe era correlato, foram enunciadas as categorias do 'normal', do 'anormal' e do 'patológico'. Estas categorias dominaram o horizonte antropológico e o campo epistemológico que orientaram os discursos e as práticas no processo de medicalização da sociedade moderna (Foucault, 1963). Esse processo se inscrevia então num registro moral e num registro teórico, que eram não apenas correlatos mas também complementares, de maneira que o campo dos valores se imbricou intimamente com o dos conceitos.

Como se articulavam aquelas categorias, nos registros da medicina social e da medicina individual? Pode-se formular isso, de forma esquemática, enunciando que seria pela normalização das anormalidades e para impedir que estas pudessem ser transformadas em patologias, que a medicina social direcionava estrategicamente as suas intervenções no espaço social. Ao lado disso, a clínica incidia diretamente sobre o patológico já constituído, visando então a cura das enfermidades.

Pode-se também destacar que foi pela mediação das categorias do normal, do anormal e do patológico, nos registros da higiene social e da clínica, que a medicina moderna realizava intervenções ao mesmo tempo 'terapêuticas' e 'preventivas'. Estas duas modalidades de intervenção se inscreveram num só conjunto e são, portanto, complementares desde o século XIX, pois era a promoção da saúde que estaria aqui sempre em pauta. Ao lado disso, pode-se afirmar ainda que a medicina 'preditiva' já estava também presente, sob a forma do esboço, numa articulação sempre cerrada com o ideário da prevenção.

Assim, no campo da medicina contemporânea ocorreu apenas uma sofisticação dessas estratégias, já presentes e bem estabelecidas desde o início do século XIX. Portanto a cura, a prevenção e a pre- 
dição foram estratégias então estabelecidas de maneira sistemática, para responder aos imperativos de uma nova ordem sociopolítica que pretendia constituir uma população bem qualificada, pois essa era efetivamente a condição concreta de possibilidade para a produção da riqueza das nações.

Tudo isso supõe que a sociedade pode se transformar - mesmo que não seja de maneira radical e por um processo revolucionário, bem entendido. Isso porque, com a modernidade, existe uma ruptura com as ordens circular e hierárquica que marcariam as sociedades pré-modernas, caracterizadas por entidades fixas e imóveis. Em decorrência, o discurso do 'progresso' foi a ideologia dominante da modernidade (Rossi, 1995; Taquieff, 2004). A idéia do progresso, com efeito, é o correlato de uma ordem social fundada na aposta permanente de sua transformação possível.

Seria assim a melhoria do gênero humano a certeza maior que perpassa a modernidade, na clássica formulação enunciada por Condorcet. Evidentemente tal melhoria e o progresso social correlato se fundariam na racionalidade científica. Estamos lançados aqui, portanto, na revolução industrial, por um lado, e no cientificismo, por outro. Estes são a face e o verso do mesmo processo, alavancas que são da ideologia do progresso e da melhoria do gênero humano.

Assim, a melhoria do gênero humano se fundaria nas normas enunciadas pela racionalidade científica. A medicina moderna foi a matriz e o paradigma das diferentes ciências humanas (Foucault, 1963), que, pelas normas que enunciaram, realizariam então a normalização do campo dos anormais, com a intenção de produzir tal melhoria. A resultante disso foi o engendramento da qualidade de vida da população, permeada pela retificação das anomalias.

Nesse contexto, a loucura e a criminalidade foram alvos privilegiados do processo de medicalização do social, pela qual a normalização se realizava. $\mathrm{O}$ asilo e a prisão foram os novos territórios constituídos para a materialização dessa estratégia. Contudo seria necessário intervir não apenas no campo da patologia, mas principalmente no da anormalidade, para que a produção da qualidade de vida da população pudesse ser mais eficaz e efetiva. Em decorrência, o conceito de 'degeneração' foi enunciado por Morel (1857) em meados do século XIX, visando justamente o campo das anormalidades que deveriam ser normalizadas. O eugenismo e o racismo foram então engendrados no campo desse projeto (Foucault, 1997), pretendendo a purificação dos degenerados e a transformação dos anormais. Daí o grande sucesso teórico e político do discurso sobre a degeneração, que apenas se sofisticou e foi bastante remanejado posteriormente, com os conceitos provenientes da genética.

Portanto se os discursos científicos enunciavam as normas para que se empreendesse o processo de medicalização do social, a certeza na melhoria do gênero humano era a sua contrapartida no re- 
gistro dos valores. Com isso, a sociedade seria passível de se transformar pela razão iluminista, que engendraria então o progresso social pela normalização dos anormais.

\section{Saber e poder no desencantamento do mundo}

Todo esse processo foi iniciado e esboçado no Renascimento, que retomou então os discursos da Antiguidade para criticar a tradição do cristianismo (Garin, 1969). Porém tal processo foi apenas formalizado nos séculos XVII e XVIII, pelo processo de 'racionalização' que dominou o Ocidente. Pela racionalização do real empreendida pelas revoluções científicas (Koyré, 1973) dos séculos XVII e XVIII, com efeito, a natureza e o mundo foram 'desencantados', para retomar a fórmula clássica de Weber (1964), enunciada em A ética protestante e o espírito do capitalismo.

Tudo isso implica dizer que a sociedade pré-moderna estava fundada no 'Mesmo', e a ordem social supunha a existência da 'hierarquia'. A 'circularidade' regulava a ordem do cosmo, pela qual o círculo, como signo que era da perfeição geométrica, restaurava perma-nentemente o 'Mesmo'. Deus regulava tudo isso, no cristianismo e na Idade Média, e os deuses empreendiam essa mesma função na Antiguidade. Portanto o mundo era sagrado e sacralizado, encantado pelos deuses, que o permeavam nas suas coordenadas fundamentais.

Como já vimos, aliás, o ideário da salvação se constituiu com o cristianismo. Isso porque no discurso deste os seres têm desde sempre um lugar determinado na estrutura hierárquica e circular do cosmo. Portanto, a salvação implicaria, para o sujeito, ser perdoado e poder assim reencontrar o seu lugar e sua posição no mundo, que teriam sido perdidos pela transgressão empreendida por aquele dos preceitos divinos. Pela purificação da alma, enfim, Deus perdoaria o infiel pelos seus pecados e lhe asseguraria a vida eterna.

Nos séculos XVII e XVIII as revoluções científicas subverteram a totalidade desse cenário sagrado. A natureza foi desencantada e dessacralizada pelo desenvolvimento da racionalidade científica. $\mathrm{O}$ cosmo finito foi então transformado no universo infinito, segundo a fórmula concisa enunciada por Koyré (1973). Foi justamente nesse contexto histórico que Descartes (1949a) e Bacon (Brahami, 2002) começaram a formular as relações intricadas entre os registros do saber e do poder, uma vez que a posse do saber implicaria a conquista e o exercício de poder sobre as coisas e os homens, e vice-versa.

Nessa imbricação original entre as ordens do saber e do poder começa a se esboçar algo de novo, a relação entre a ciência e a técnica. Se esses registros eram até então independentes e autônomos, eles passaram agora a convergir e se articular intimamente, de maneira tal que os discursos das ciências passaram a ser progressi- 
vamente o fundamento das práticas técnicas. A Revolução Industrial, no século XIX, foi o ponto de chegada triunfante desse processo de imbricação entre a ciência e a técnica, pelo qual os registros do saber e do poder estariam intimamente articulados. Se o maquinismo industrial subverteu as relações sociais e instituiu novas modalidades de trabalho, por um lado, esse mesmo maquinismo delineou o campo material do discurso sobre o progresso, por outro.

No registro do saber, as ciências do inorgânico se desenvolveram inicialmente, destacando-se aqui a astronomia do universo infinito e a física, com a mecânica. Ao lado disso, a astronomia e a física se unificaram no mesmo território e racionalidade, pois os registros lunar e sublunar do antigo cosmo se inscreveram agora no universo infinito. Em seguida, a química começou a se formalizar, diferenciando-se paulatinamente da alquimia.

No discurso filosófico, em contrapartida, Descartes (1949c) enunciou a oposição existente entre os registros do pensamento e da extensão, construindo então o modelo teórico da máquina. Tal modelo foi transformado em 'paradigma epistemológico' do conhecimento, de forma que, nesse contexto teórico, o vivente foi assim reduzido ao registro da máquina. Foi em decorrência disso, aliás, que La Mettrie construiu o conceito de 'homem-máquina', estendendo então ao homem o paradigma epistemológico da natureza enunciado por Descartes.

\section{Da força vital ao instinto}

Evidentemente o 'vivente' não poderia ter nenhuma especificidade nesse campo epistemológico, reduzido que foi ao modelo teórico da máquina. Somente com Leibniz começou-se a enunciar os conceitos específicos sobre o vivente, procurando diferenciar este dos corpos inorgânicos. Isso implicou, portanto, a crítica sistemática do maquinismo cartesiano. É preciso ainda considerar que não estaríamos mais aqui no campo da 'estática' dos corpos, mas no da sua 'dinâmica'. A relação dos corpos entre si, num campo imantado de forças que agem e interagem continuamente entre si delineou, enfim, o novo campo da dinâmica.

Nesse contexto foi enunciado o conceito de 'força vital', que marcaria o vivente enquanto tal, diferenciando-o dos corpos inorgânicos (Pichot, 1994). Em seguida a força vital passou a ser definida nas suas propriedades fundamentais, de forma a opor-se às demais forças existentes na natureza bruta. A 'excitabilidade' e a 'irritabilidade' passaram então a caracterizar o vivente, sendo as suas marcas inconfundíveis. Começou-se a esboçar, assim, a existência de um terceiro registro do saber, diferente dos registros do pensamento e da extensão enunciados por Descartes. A especifi- 
cidade do registro biológico se esboçou de maneira paulatina e imperativa, tendo na força vital o seu fundamento e na excitabilidade e irritabilidade as suas propriedades básicas.

O discurso do 'vitalismo' foi se constituindo desde então, sobre tais alicerces conceituais, como aquilo que sustentava a especificidade do vivente perante a natureza do inorgânico. Com isso, o vitalismo foi a ideologia científica dominante sobre a biologia nascente, por fundar tal especificidade na força vital (Pichot, 1994). O mesmo vitalismo se transformou também numa ideologia fundamental da medicina nos séculos XVIII e XIX. Na França, com efeito, a escola médica de Montpellier era essencialmente vitalista, destacando-se justamente por isso (Pichot, 1994). Da mesma forma, com Claude Bernard a fisiologia foi construída sobre o mesmo solo vitalista (Canguilhem, 1968a), sobre o qual ele enunciou também os pressupostos da medicina experimental no século XIX (Canguilhem, 1968b).

Foi também nesse contexto teórico que o conceito de 'organismo' foi forjado, sendo o pressuposto da fisiologia e da medicina experimental enunciados por Claude Bernard. O que estava em pauta era a idéia de uma relação ativa e contínua do vivente com o seu meio ambiente, pela qual o imperativo da vida se afirmaria sempre pelas regulações e constâncias do meio interno do organismo, que se defrontaria permanentemente com as variações do meio externo.

Deslocando-nos agora dos discursos da biologia e da medicina para os da psicologia e da psicopatologia, podemos destacar alguns outros destinos e derivações que teve a ordem vital na sua especificidade teórica.

Antes de tudo, construiu-se a relação entre os registros do espírito e da vitalidade, para que o psiquismo pudesse ser concebido agora em outras bases, de maneira que este não mais se restringisse à ordem do espírito. Assim, o registro da vitalidade foi o desaguadouro teórico da antiga problemática das 'paixões da alma', e os discursos sobre os afetos e os sentimentos passaram a ser enunciados em outras bases conceituais, fundados agora na ordem vital (Descartes, 1949b; Besnier, Moreau, Renault, 2003).

Seriam os afetos e os sentimentos regulados pelo pensamento, para o correto funcionamento do entendimento? Ou, então, por mais que o pensamento devesse sempre regular os sentimentos, estes resistiriam e manteriam ainda, no limite, alguma forma de autonomia? Pode-se depreender, disso, como a 'tensão' e até mesmo o 'conflito' foram então estabelecidos entre os registros do pensamento e da vitalidade, de maneira inequívoca.

O discurso psicopatológico também se insinuou nesse mesmo campo, pelo viés da não-regulação do registro das paixões pelo registro do pensamento. A doença mental não seria justamente a rebeldia das paixões contra a regulação do espírito realizada pela 
razão? A alienação mental não revelaria de maneira inequívoca o domínio das paixões desenfreadas no psiquismo, contrapondo-se às regulações da razão e afirmando o que existiria de incontornável (Esquirol, 1838) na autonomia das paixões? O tratamento moral da alienação mental não visaria justamente restaurar o domínio da razão sobre as paixões desenfreadas dos loucos, para que se pudesse corrigir tal desmesura dos afetos? (Falret, 1864; Foucault, 2003).

Assim, as noções de saúde psíquica e de normalidade implicariam o domínio efetivo da razão sobre as paixões, marcas estas do registro da animalidade/vitalidade presentes no psiquismo humano. As anomalias mentais seriam todas derivadas do registro da vitalidade e deveriam ser meticulosamente corrigidas pelos limites a serem estabelecidos à autonomia das paixões, para que a razão pudesse então se impor, de forma triunfante, como princípio dominante do psiquismo.

Foi no campo dessa problemática teórica que o então recente modelo biológico da 'evolução' foi incorporado nos discursos da psicologia e da psicopatologia, na segunda metade do século XIX (Foucault, 1962). Assim, se as perturbações do espírito passaram a ser concebidas como modalidades de 'involução', das formas superiores do espírito em direção às formas inferiores, tal involução seria devida à perda do domínio da razão sobre os registros inferiores da vitalidade. Tudo isso supunha, é claro, um modelo evolucionista de ordem neuropsicogenética do espírito, pelo qual as formas superiores de organização regulariam as inferiores de forma contínua e inequívoca. Portanto as perturbações neurológicas e psicopatológicas seriam modalidades de involução do organismo, nas quais o organismo retomaria as formas inferiores de organização. Foi o conceito de 'regressão' que se enunciou então, estando patente e efetivamente operativo no discurso teórico de H. Jackson (Nassif, 1977).

O discurso da degeneração se inscreveu, de fato e de direito, nesse campo teórico. Foi por tal viés que o campo das anomalias e patologias psíquicas e somáticas foi redistribuído, de maneira que os conceitos de evolução e involução estão no cerne dessa construção teórica. No seu fundamento, contudo, o que estava em pauta era a oposição entre os registros do espírito e da vitalidade/animalidade, que regularia, em última instância, o campo conceitual dessa construção teórica (Foucault, 1971).

Porém isso ainda não é tudo, no que concerne a esta problemática. A sua inflexão decisiva foi a constituição do conceito de 'instinto', que passou a assumir desde então uma posição decisiva nos discursos da biologia, da psicologia e da psicopatologia.

Pela 'derivação' dos conceitos de força vital e de ordem vital, que marcariam a especificidade do vivente, constituiu-se o conceito de instinto como marca por excelência e inconfundível da ani- 
malidade. Assim, o instinto seria o signo primário da ordem da vida, a infra-estrutura íntima e essencial que moveria o vivente e, dessa maneira, afirmaria o primado da vida.

Ao lado disso, estamos lançados aqui na transmutação última da força vital, que de sua matriz biológica se disseminou também para os discursos da psicologia e da psicopatologia. As anomalias e as patologias do psíquico encontrariam, nesse registro da natureza biológica e da animalidade, a sua partitura fundamental, na qual a vida se manifestaria de forma pura.

Foi no campo da criminalidade e delinqüência que a psicopatologia nascente construiu a sua legitimidade teórica, destacando a existência de um instinto criminoso que estaria na gênese dos atos criminais impossíveis de serem concebidos pela racionalidade jurídica. Foi por esse viés que a psiquiatria definiu as suas posições social, institucional e teórica, na intercessão com o campo do direito penal. A enquete psiquiátrica dos atos criminais passou assim a se impor no campo jurídico, constituindo o discurso da criminologia e da psiquiatria forense. Além disso, a psiquiatria também constituiu sua especificidade teórica, deslocando-se agora do campo da higiene social para o da clínica (Foucault, 1999). Para isso, no entanto, o conceito de instinto foi a instância crucial, derivação teórica última do conceito de força vital.

\section{Vitalismo e normatividade no sexual}

A constituição do campo psicanalítico no final do século XIX, com o discurso freudiano, foi tecida nos registros da vitalidade e do instintual para conceber o psiquismo nessa articulação teórica. Porém tal construção teórica implicou uma leitura anterior, pela qual a linguagem seria fundante do psiquismo. Por isso o discurso seria sempre um instrumento crucial da cura, tanto no registro das perturbações psíquicas quanto no das somáticas (Freud, 1985b). Nos dois movimentos teóricos aqui considerados, no entanto, o que estava sempre em pauta era a crítica do positivismo médico e do discurso da neuropsiquiatria.

Assim, no ensaio sobre as afasias, de 1891, Freud enunciou a tese ousada de que o psiquismo seria um 'aparelho de linguagem' (Freud, 1953). Ainda no mesmo ano, no ensaio sobre o "Tratamento psíquico" (Freud, 1985b), formulou que o discurso seria o instrumento crucial da cura das enfermidades somáticas e psíquicas. Evidentemente esses dois ensaios são complementares: pelo primeiro delineia-se o campo teórico da problemática da linguagem para conceber o psíquico, enquanto que o segundo desenha os desdobramentos clínicos dessa proposição.

A efetividade terapêutica da linguagem teria sido esquecida e silenciada pela tradição recente do positivismo e do cientificismo 
médicos, não obstante a sua presença constante nas práticas terapêuticas ao longo da história da medicina. As curas miraculosas que ocorriam no final do século XIX, de base religiosa, seriam decorrentes dos efeitos terapêuticos do discurso que circularia entre as figuras do religioso e do enfermo. Evidentemente toda essa construção teórica e clínica, na qual se articulava de maneira sistemática a concepção do aparelho de linguagem e o efeito terapêutico dela, é contemporânea das práticas hipnótica e sugestiva que Freud empreendia então clinicamente, inscrito que estava nas tradições terapêutica de Charcot (Freud, 1978a) e de Bernheim (Freud, 1978b).

Desde 1893, no entanto, Freud iniciou outro percurso clínico, com a psicoterapia catártica, em colaboração com Breuer. Assim, na "Comunicação preliminar" (Freud, Breuer, 1971) enunciou a hipótese traumática sobre as psiconeuroses, introduzindo os registros dinâmico e econômico na leitura do psiquismo. Em decorrência, os conceitos de defesa e de divisão psíquica (Freud, 1973e, 1973f; Freud, Breuer, 1971) foram formulados, logo em seguida, de forma a se delinear no discurso freudiano a idéia da existência de uma 'outra cena', que estaria além dos registros da consciência e do eu. $\mathrm{O}$ registro do inconsciente estava assim já esboçado, como ponto de articulação decisivo dos conceitos aqui enunciados.

Foi pelo enunciado da existência dos registros dinâmico e econômico no psiquismo que o discurso freudiano foi conduzido a retificar a hipótese inicial sobre a existência do aparelho de linguagem. Este foi transformado, no "Projeto de uma psicologia científica" (Freud, 1973a), no conceito de 'aparelho psíquico'. Diferentemente do aparelho de linguagem, com efeito, o aparelho psíquico seria também atravessado pelas dimensões 'dinâmica' e 'econômica', além da dimensão 'tópica'. A conflituosidade foi então inscrita no fundamento do aparelho psíquico, sendo considerada desde agora como a fonte inesgotável para a produção da divisão psíquica e das defesas.

Tudo isso se desdobrou na construção do aparelho psíquico fundado no 'inconsciente', por um lado, e na 'sexualidade', por outro. Para isso, contudo, a sexualidade foi descolada de sua anterior origem traumática, inscrita agora na perversidade polimorfa presente na sexualidade infantil, modelada por fantasmas (Freud, 1962). A contrapartida disso foi a formulação de que o dito aparelho seria constituído por um conjunto de 'traços' psíquicos, sem nenhum sabor traumático e colocados em movimento pelo 'desejo' (Freud, 1976). Portanto, as pulsões e os traços psíquicos seriam os constituintes fundamentais do aparelho psíquico, esboçado então pelo discurso freudiano.

Assim, pode-se depreender facilmente a presença de um duplo movimento crítico no discurso freudiano. Pelo enunciado do conceito de traço psíquico, realizou a crítica da teoria da 'lesão' nas 
perturbações mentais, empreendendo então uma ruptura crucial com a teoria da localização anatômica, que dominou a tradição psiquiátrica no século XIX (Hecaen, Lanteri-Laura, 1977; LanteriLaura, 1970). Ao lado disso, pelo enunciado do conceito de sexualidade perverso-polimorfa, realizou a crítica da teoria da degeneração (Foucault, 1976). Com efeito, o traço psíquico assumiu, no discurso freudiano, o lugar epistêmico até então outorgado à lesão anatômica, da mesma forma que a sexualidade infantil assumiu a posição epistemológica decisiva de substituir a biologia eugênica da degenerescência.

No entanto o conceito de pulsão se inscreveu na linhagem teórica do conceito de instinto, sendo deste uma derivação importante. Evidentemente a pulsão não é literalmente o instinto. Por isso mesmo, citei a idéia de derivação no sentido epistemológico do termo, pois se inscreveram ambos na mesma matriz teórica. Assim, desde os "Três ensaios sobre a teoria da sexualidade", Freud esboçou uma série de características do conceito de pulsão que o diferenciavam do conceito de instinto (Freud, 1962), principalmente a inespecificidade do objeto da pulsão e sua multiplicidade. Porém tanto o conceito de instinto quanto o de pulsão se inscreveram na matriz teórica da força vital. Como o que estava em questão, no discurso freudiano de então, era a pulsão sexual, a sexualidade seria agora a materialização maior da vitalidade, em oposição tanto ao registro do espírito quanto ao da natureza inorgânica.

A sexualidade seria, então, o signo mais visível e eloqüente da força vital no aparelho psíquico, de maneira que nos primórdios da psicanálise o discurso freudiano estava marcado pelo discurso do vitalismo. É em decorrência disso que as referências a Claude Bernard são múltiplas em A interpretação dos sonhos (Freud, 1976), principalmente no que concerne à relatividade da oposição entre os registros do normal e do patológico. Como conseqüência das variações intensivas no campo da economia da sexualidade, com efeito, a relatividade da oposição entre o normal e o patológico agora se impunha, por esse registro fundamental do aparelho psíquico.

Portanto, uma das referências teóricas iniciais do discurso freudiano era indiscutivelmente a biologia vitalista. A sexualidade dominava o funcionamento psíquico, mesmo que as pulsões de autoconservação (Freud, 1962), inicialmente, e as pulsões do eu (Freud, 1973d), posteriormente, se opusessem às pulsões sexuais na dinâmica estabelecida pelo conflito psíquico. Por isso mesmo, aliás, a psicanálise foi então criticada por ser eminentemente pansexualista.

Como o que estava então em pauta era a afirmação das pulsões sexuais enquanto tal, e sendo estas a materialização maior da força vital, as impossibilidades disso seriam constituintes das anomalias e das patologias do psiquismo, que se traduziriam pela produção 
de sintomas. Em decorrência, seria preciso deixar circular sem obstáculos a sexualidade, pela qual a dissolução dos sintomas se realizaria e a cura seria então produzida.

No ensaio inicial sobre o mal-estar na cultura - "A moral sexual 'civilizada' e a doença nervosa dos tempos modernos" (Freud, 1973b) -, o discurso freudiano indicou como foram as repressões ao livre movimento e circulação das pulsões sexuais, realizadas em diferentes momentos da história do Ocidente e que se efetuaram pelas instituições sociais, que seriam as condições de possibilidade das ditas 'doenças nervosas'. Como esse processo teria se incrementado na modernidade, poderia ser assim interpretado o incremento das perturbações psíquicas nesse contexto histórico. Seria esta, enfim, a conseqüência maior da moral monogâmica.

A fundamentação metapsicológica dessa leitura freudiana, no entanto, foi realizada precocemente no "Projeto de uma psicologia científica", no tópico inicial dessa obra, já na sua primeira parte (Freud, 1973a), o que implica reconhecer que essa assunção teórica, realizada logo no começo desse livro crucial, foi constituinte da primeira metapsicologia freudiana. Foi na mesma obra, aliás, que o discurso freudiano transformou o aparelho de linguagem em aparelho psíquico, introduzindo as dimensões dinâmica e econômica da metapsicologia.

O que enunciou então o discurso freudiano? Logo após formular a existência do 'principio da inércia' como primordial no psiquismo - a tendência originária do aparelho psíquico para descarregar todas as excitações nele operantes, de modo a livrar-se da inquietude que isso produzia -, Freud ponderou que se as coisas acontecessem assim a morte se imporia sobre o vivente, tornando então impossível a instauração da ordem da vida.

Portanto para Freud essa formulação inicial seria impossível, devendo, pois, ser retificada. O discurso freudiano realizou então uma correção, transformando o princípio da inércia no da constância, pelo qual apenas uma parte das excitações seria descarregada e as demais retidas, em nome sempre da manutenção da ordem da vida. Em decorrência, o princípio do prazer seria dominante no psiquismo desde os seus primórdios, em nome da 'urgência da vida' (Freud, 1973a). A afirmação da vida não poderia então ser absolutamente colocada em questão, orientado que estava o discurso freudiano pelos pressupostos da biologia vitalista. O que se afirmava, enfim, era a fundação da ordem vital no registro da sexualidade, regulada aquela pelo primado do princípio do prazer.

É importante destacar e evocar devidamente que a descrição inicial do vivente considerada pelo discurso freudiano retoma a mesma descrição teórica esboçada nos séculos XVII e XVIII, na qual a matéria viva, em oposição à matéria inorgânica, seria caracterizada pela excitabilidade e pela irritabilidade. O que existe de novidade 
no discurso freudiano são os destinos a serem oferecidos para essa excitabilidade e irritabilidade, para que a ordem da vida possa efetivamente se afirmar, dada a inquietude que essas inequivocamente provocariam. A regulação disso pelo principio do prazer se enunciou então, inscrevendo assim a sexualidade na sua articulação íntima com a força vital, pelo imperativo incontornável da 'urgência da vida' (Freud, 1973a).

Portanto, na inauguração da psicanálise e na sua primeira metapsicologia, o discurso freudiano acreditava não apenas que a vida era soberana e imperativa, mas também que ela se impunha inequivocamente pelo viés da sexualidade. Daí ser primordial o princípio do prazer no aparelho psíquico. A biologia freudiana era incontestavelmente vitalista.

Assim, da mesma forma que Canguilhem enunciou o conceito da 'normatividade' do organismo, no intercâmbio constante deste com o meio ambiente, Freud (1966) formulava também que existiria a normatividade do sexual, que se inscrevia entre os registros do somático e do psíquico. A existência de uma homeostase psicossomática, enfim, estava presente no horizonte teórico da primeira metapsicologia freudiana, delineando a sua concepção da clínica e da cura, e de maneira similar Canguilhem formulou uma leitura da clínica fundada na normatividade vital.

\section{Mortalismo e normalização}

Entretanto, com os impasses teóricos e clínicos que o sadismo e o masoquismo já indicavam, entre outros, Freud foi obrigado a colocar em questão a sua metapsicologia inicial, enunciando uma nova teoria das pulsões, fundada agora na oposição entre a pulsão de vida e a pulsão de morte. Assim, se em "Além do princípio do prazer", em 1920, Freud (1982) enunciou o novo dualismo pulsional, foi apenas em "O problema econômico do masoquismo" (Freud, 1973c), em 1924, que empreendeu a crítica sistemática de sua primeira metapsicologia, formulada nas primeiras páginas do "Projeto de uma psicologia científica".

Num estilo categórico, Freud (1973c) afirmou que cometera anteriormente um 'erro' ao enunciar o primado do princípio da constância e descartar a existência do princípio da inércia. Isso porque a ação inaugural do vivente seria efetivamente o da descarga total das excitações, para instaurar assim a quietude, num movimento efetivo em direção à morte e ao registro do inorgânico. Porém o princípio da inércia era agora nomeado de 'princípio do nirvana', pelo qual o discurso freudiano esboçava pela quietude nirvânica o retorno ao silêncio imperturbável do registro natural do inorgânico. Seria necessária a ação do outro humano para que a vida biológica se tornasse possível, sem a qual a morte se imporia sobre o vivente 
de maneira inequívoca. A pulsão de vida começaria assim o seu trabalho constante para o domínio e a regulação da pulsão de morte, que seria sempre recomeçado, pois sem essa ação permanente a morte triunfaria sobre a vida.

Isso implica reconhecer que é a morte que se encontra no fundamento da vida e no fundamento da nova biologia freudiana, em oposição à aposta vitalista inicial presente no discurso freudiano. O vivente tende para o inorgânico e para a vertigem da morte, para instaurar a quietude nirvânica na ausência absoluta de qualquer excitabilidade. Nesse contexto, o movimento em direção à vida se constituiria apenas num segundo momento, pela ação constante de outro, sem a qual aquela seria então impossível. Em decorrência, o princípio do prazer seria o vetor da ordem da vida, que pela erogenidade regularia o movimento inicial e imperativo em direção à morte.

Com esse pressuposto 'mortalista' (Foucault, 1963), o discurso freudiano se aproxima da biologia antivitalista de Bichat (1994), posto que para este "a vida é o conjunto de forças que se opõem à morte", no qual a morte é agora o movimento primordial em relação à vida. A vida seria assim derivada da ação constante do outro, que a transmitiria pelos interstícios da pulsão de vida.

Lacan, em ensaio inicial intitulado "Além do princípio da realidade" (Lacan, 1966), em que procurava conceber o alcance do conceito de pulsão de morte, formulara já como a biologia freudiana do final de seu percurso se contrapunha a uma perspectiva homeostática e vitalista. O que estaria em pauta, portanto, com o intrigante conceito de pulsão de morte era uma formulação que se aproximava da concepção biológica de Bichat.

Isso implica dizer que, em tal contexto, a cura passa pelo domínio e ligação constante da pulsão de morte pela pulsão de vida, de modo que o movimento mortalista do vivente em direção ao inorgânico poderia ser revertido na afirmação desejante da vida. O ideário da normatividade sexual, presente na primeira metapsicologia freudiana, desaparece aqui definitivamente, diante do reconhecimento eloqüente do primado do movimento em direção à morte, presente agora no psiquismo.

Nessa perspectiva, foi a finitude do sujeito que se colocou em pauta, de maneira crucial, uma vez que apenas a morte pode definir o limite incontornável para o vivente e para o sujeito. Em contrapartida, foi também nesse contexto teórico que a cura se transformou num projeto quase infinito e no limite quase não mais alcançável, não mais finito, como era nos primórdios da psicanálise. Com efeito, em um dos seus últimos ensaios - "Análise com fim e análise sem fim" - Freud (1985a) indicou bem isso, confrontado que estava com os impasses para a regulação efetiva da pulsão de morte pela pulsão de vida. Seria, portanto, o trabalho silencioso da pulsão de 
morte o que faria uma oposição constante, no psiquismo, ao trabalho psicanalítico, delineando agora o esboço da análise sem fim.

Toda a psicanálise pós-freudiana foi e é ainda marcada por essa problemática, com o prolongamento quase infinito da duração da análise. O que a experiência psicanalítica pode ainda propor não é a cura (guérison), no sentido médico do termo, mas uma experiência de cura (cure) na qual a pulsão de vida pode e deve se contrapor à pulsão de morte, num psiquismo não mais atravessado pela homeostasia e a normatividade do sexual.

Em contrapartida, éa sombra funesta da 'normalização' (Foucault, 1963) o que se projeta decisivamente sobre a experiência psicanalítica, no esforço insistente e sempre reiterado do domínio da pulsão de vida sobre a pulsão de morte, empreendido pelo processo analítico. Como é a retórica da guerra o que esboça agora o cenário da experiência analítica, na qual certamente "vão vencer os batalhões mais fortes" (Freud, 1985a) no confronto indecisivo entre as pulsões fundamentais, a normalização se coloca para o analista como uma tentação sempre possível, para que possa assim suspender a conflagração em curso. Poder suportar agora a presença efetiva da guerra, sem recair na sedução fácil da normalização constitui, enfim, o desafio maior da aventura psicanalítica, e alguns certamente sucumbem nas bordas trágicas desse fio da navalha.

\section{REFERÊNCIAS BIBLIOGRÁFICAS}

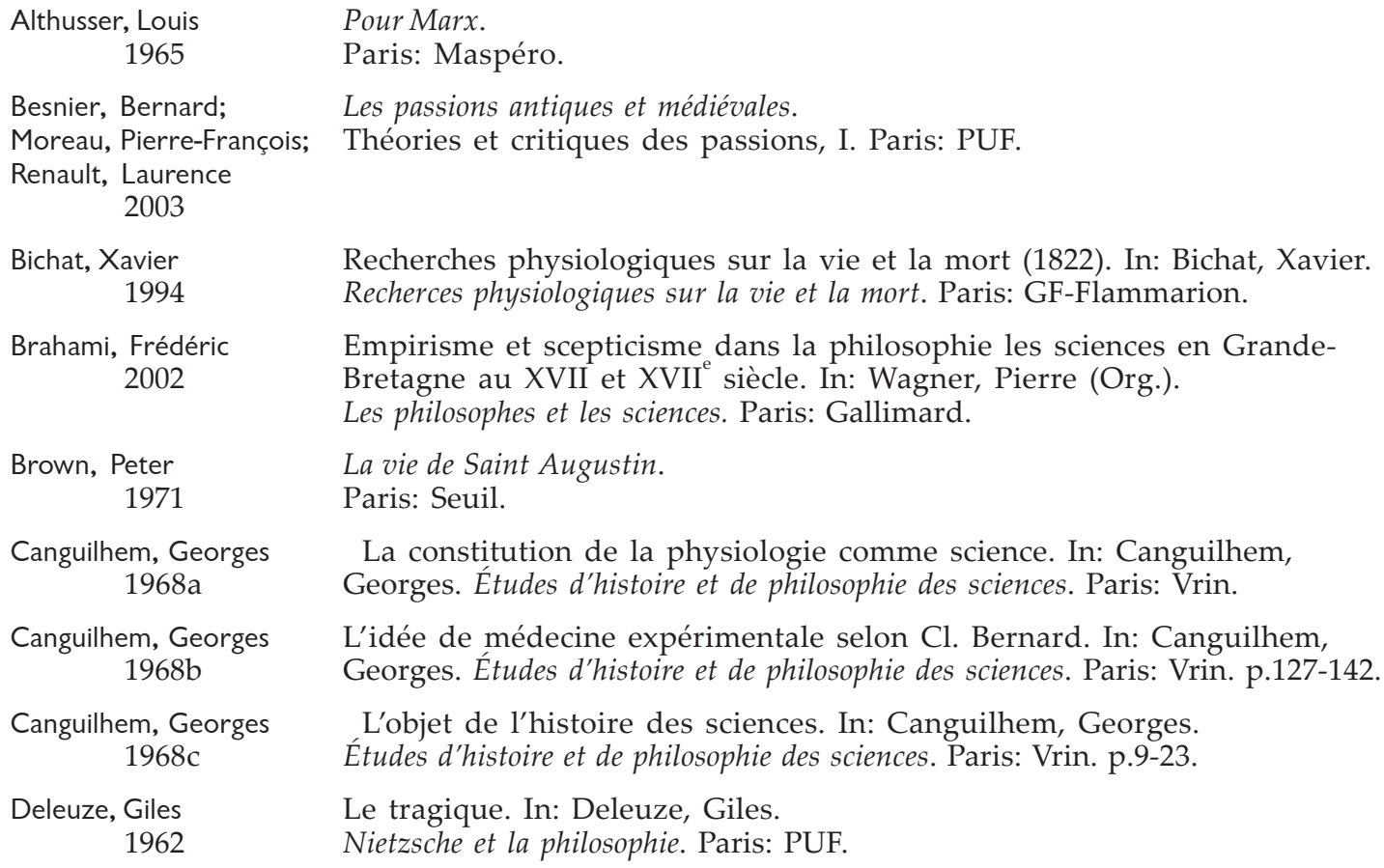

Recherches physiologiques sur la vie et la mort (1822). In: Bichat, Xavier. Recherces physiologiques sur la vie et la mort. Paris: GF-Flammarion.

Empirisme et scepticisme dans la philosophie les sciences en GrandeBretagne au XVII et XVII siècle. In: Wagner, Pierre (Org.). Les philosophes et les sciences. Paris: Gallimard.

La vie de Saint Augustin.

Paris: Seuil.

La constitution de la physiologie comme science. In: Canguilhem, Georges. Études d'histoire et de philosophie des sciences. Paris: Vrin.

L'idée de médecine expérimentale selon $\mathrm{Cl}$. Bernard. In: Canguilhem, Georges. Études d'histoire et de philosophie des sciences. Paris: Vrin. p.127-142.

L'objet de l'histoire des sciences. In: Canguilhem, Georges. Études d'histoire et de philosophie des sciences. Paris: Vrin. p.9-23.

Deleuze, Giles 1962 


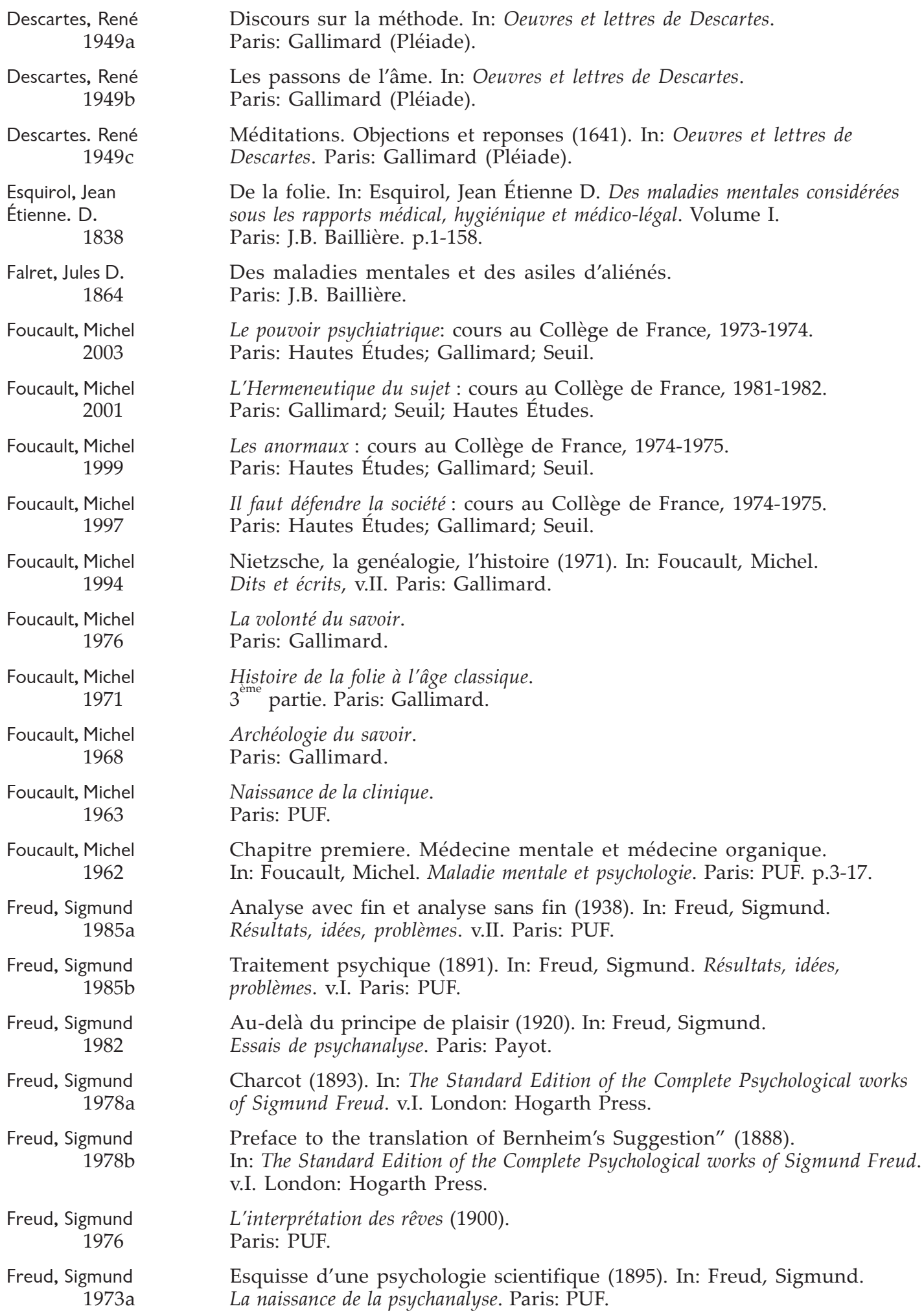

Discours sur la méthode. In: Oeuvres et lettres de Descartes. Paris: Gallimard (Pléiade).

Les passons de l'âme. In: Oeuvres et lettres de Descartes. Paris: Gallimard (Pléiade).

Méditations. Objections et reponses (1641). In: Oeuvres et lettres de Descartes. Paris: Gallimard (Pléiade).

De la folie. In: Esquirol, Jean Étienne D. Des maladies mentales considérées sous les rapports médical, hygiénique et médico-légal. Volume I.

Paris: J.B. Baillière. p.1-158.

Des maladies mentales et des asiles d'aliénés. Paris: J.B. Baillière.

Le pouvoir psychiatrique: cours au Collège de France, 1973-1974. Paris: Hautes Études; Gallimard; Seuil.

L'Hermeneutique du sujet : cours au Collège de France, 1981-1982. Paris: Gallimard; Seuil; Hautes Études.

Les anormaux: cours au Collège de France, 1974-1975.

Paris: Hautes Études; Gallimard; Seuil.

Il faut défendre la société : cours au Collège de France, 1974-1975. Paris: Hautes Études; Gallimard; Seuil.

Nietzsche, la genéalogie, l'histoire (1971). In: Foucault, Michel. Dits et écrits, v.II. Paris: Gallimard.

La volonté du savoir.

Paris: Gallimard.

Histoire de la folie à l'âge classique. $3^{\text {eme }}$ partie. Paris: Gallimard.

Archéologie du savoir. Paris: Gallimard.

Naissance de la clinique. Paris: PUF.

Chapitre premiere. Médecine mentale et médecine organique. In: Foucault, Michel. Maladie mentale et psychologie. Paris: PUF. p.3-17.

Analyse avec fin et analyse sans fin (1938). In: Freud, Sigmund. Résultats, idées, problèmes. v.II. Paris: PUF.

Traitement psychique (1891). In: Freud, Sigmund. Résultats, idées, problèmes. v.I. Paris: PUF.

Au-delà du principe de plaisir (1920). In: Freud, Sigmund.

Essais de psychanalyse. Paris: Payot.

Charcot (1893). In: The Standard Edition of the Complete Psychological works of Sigmund Freud. v.I. London: Hogarth Press.

Preface to the translation of Bernheim's Suggestion" (1888). In: The Standard Edition of the Complete Psychological works of Sigmund Freud. v.I. London: Hogarth Press.

L'interprétation des rêves (1900). Paris: PUF.

Esquisse d'une psychologie scientifique (1895). In: Freud, Sigmund. La naissance de la psychanalyse. Paris: PUF. 
JOEL BIRMAN

Freud, Sigmund

1973b

Freud, Sigmund

1973c

Freud, Sigmund

1973d

Freud, Sigmund

1973e

Freud, Sigmund

1973f

Freud, Sigmund 1966

Freud, Sigmund 1962

Freud, Sigmund 1953

Freud, Sigmund;

Breuer, Joseph

1971

Garin, Eugenio 1969

Hecaen, Henri; Lanteri

Laura, Georges 1977

Koyré, Alexandre 1973

Lacan, Jacques 1966

Lanteri-Laura, Georges 1970

Morel, Bénédict. A. 1857

Nassif, Jacques 1977

Nietzsche, Friedrich 1977

Pichot, André 1994

Rossi, Paolo 1995

Taquieff, Pierre-Andre 2004

Weber, Max 1964
La morale sexuelle 'civilisée' et la maladie nerveuse des temps modernes (1908). In: Freud, Sigmund. La vie sexuelle. Paris: PUF.

Le problème économique du masochisme (1924). In: Freud, Sigmund. Névrose, psychose, perversion. Paris: PUF.

Le trouble psychogène de la vision dans la conception psychanalytique (1910). In: Freud, Sigmund. Névroses, psychose et perversion. Paris: PUF.

Les psychonévroses de défense (1894). In: Névrose, psychose et perversion. Paris: PUF.

Nouvelles remarques sur les psychonévroses défense (1896).

In: Névrose, psychose et perversion. Paris: PUF.

Le normal et le pathologique (1943).

Paris: PUF.

Trois essais sur la théorie de la sexualité (1905).

Paris: Gallimard.

On aphasia (1891).

New York: International Universities Press.

Communication préliminaire (1893). In: Freud, Sigmund.

Études sur l'hystérie (1895). Paris: PUF.

Moyen Âge et Renaissance.

Paris: Gallimard.

Evolution des connaissances et des doctrines sur les localizations cerébrales.

Paris: Desclée de Brouwer.

Du monde clos à l'univers infini.

Paris: Gallimard.

Au-delà du 'principe de realité' (1936). In: Lacan, Jacques.

Écrits. Paris: Seuil.

Histoire de la phrénologie.

Paris: PUF.

Traité des dégenerescences physiques, intellectuelles et morales de l'espèce humaine et des causes qui produisent ces variétés maladives. Paris: J. B. Baillière.

Freud: l'inconscient.

Paris: Galilee.

Naissance de la tragédie.

Paris: Gallimard.

Présentation. In: Bichat, Xavier. Recherches physiologiques sur la vie et la mort. Paris: GF-Flammarion.

Naufrágios sem espectador: a idéia de progresso.

São Paulo: Ed. Unesp.

Le sens du progress. Une approche historique et philosophique.

Paris: Flammarion.

L'éthique protestante et l'esprit du capitalisme.

Paris: Plon. 